\title{
La fiscalidad en las Mipymes de la región del Austro, en el contexto de la pandemia del COVID-19
}

\author{
DOI: https://doi.org/10.33262/ap.v3i3.71
}

\begin{abstract}
(c) (i) (ㅇ)
Taxation in MSMEs in the Austro region, in the context of the COVID-19 pandemic.
\end{abstract}

Edison Becerra Molina. ${ }^{1}$, María Eliza Flores Flores. ${ }^{2}$ \& Gina Cuadrado Sánchez. ${ }^{3}$

\begin{abstract}
Introduction. Taxation is the basic resource for financing public spending, it is time to focus on consumption, and propose tax measures according to the current reality. Objective. Analyze the tax regulations for the effective management of information, given the uncertainty of COVID-19 in the region 6. Methodology. The research design started from the positivist research paradigm, type of research based on a nonexperimental and transectional field design with documentary support, descriptive research level, the population was 77,289 and the sample 471 , the questionnaire instrument was used, it was validated through the judgment of experts with experience in the area of taxation, accounting and methodology, qualifying validity, clarity, coherence, and relevance. Results. Regarding payment deferral $12.44 \%$, maturity extension $15.63 \%$, tax simplification $8.91 \%$, tax reduction $1.51 \%$ progressivity of taxes $2.86 \%$, totaling trends $41.35 \%$, this implies that taxpayers were waiting to be able to comply with their obligations, and / or request a payment plan, and benefit from incentives, likewise $38.32 \%$, have not benefited from any stimulus, perhaps due to ignorance, particularly the sector microentrepreneurs who pay $2 \%$ of income tax on income, whether they have had gains or losses during the year, and on the other due to the economic crisis, and the lack

\footnotetext{
1 Universidad Católica de Cuenca, Carrera de Contabilidad y auditoría, provincia Azuay, código, jbecerram@ucacue.edu.ec, Orcid ID:000-0002-6397-9493

2 Universidad Católica de Cuenca, Carrera de Contabilidad y auditoría, provincia Azuay, código, mefloresf@ucacue.edu.ec, Orcid ID: 0000-0002-7348-4523

3 Universidad Católica de Cuenca, Carrera de Contabilidad y auditoría, provincia Azuay, código, gcuadro@ucacue.edu.ec, Orcid ID: 0000-0002-4259-4906
} 
of cash flow, also 20.34\%, of the MSMEs have cleared tax procedures through the online SRI portal. Conclution. The elimination of the income tax calculated on the sales of microenterprises will be important since it considerably affects the cash flow, and it is convenient to review the taxpayer's ability to pay.

Keywords: COVID-19, regulations, taxes, MSMEs, taxpayers.

\section{Resumen}

Introducción. La fiscalidad es el recurso básico para el financiamiento del gasto público, es hora de enfocar el consumo, y proponer medidas tributarias acorde a la realidad actual. Objetivo. Analizar la normativa tributaria para el manejo eficaz de la información, ante la incertidumbre del COVID-19 en la región 6. Metodología. El diseño de la investigación partió del paradigma de investigación positivista, tipo de investigación basada en un diseño de campo no experimental y transeccional con apoyo documental, nivel de investigación descriptiva, la población fue 77.289 y la muestra 471, se utilizó el instrumento del cuestionario, el mismo fue validado mediante juicio de expertos con experiencia en el área de tributación, contabilidad y metodología, calificando validez, claridad, coherencia, y relevancia. Resultados. Con respecto al diferimiento de pago $12,44 \%$, prórroga de vencimiento $15,63 \%$, simplificación tributaria $8,91 \%$, reducción tributaria $1,51 \%$ progresividad de tributos $2,86 \%$, totalizando las tendencias $41,35 \%$, esto implica que los contribuyentes estuvieron a la espera de poder cumplir con sus obligaciones, y/o solicitar un plan de pagos, y favorecerse de los incentivos, igualmente $38,32 \%$, no se ha acogido a ningún estímulo, talvez por desconocimiento, particularmente el sector microempresarial que pagan $2 \%$ del impuesto a la renta sobre los ingresos, sea que hayan tenido ganancias o pérdidas durante el año, y por otra debido a la crisis económica, y a la falta del flujo del efectivo, igualmente 20,34\%, de las Mipymes ha dado salida a los trámites tributarios a través del portal del SRI en línea. Conclusión. Será importante la eliminación del impuesto a la renta calculado sobre las ventas de las microempresas ya que afecta considerablemente al flujo de efectivo, y es conveniente revisar la capacidad contributiva del contribuyente.

Palabras claves: COVID-19, normativa, impuestos, Mipymes, contribuyentes.

\section{Introducción}

El Covid-19 ha cambiado nuestra percepción de ver el mundo por todas sus consecuencias en varios ámbitos, es por esto que nuestro país ha sido afectado en el campo económico debido al descenso de las ventas y la falta de liquidez de las micro, pequeñas, medianas y grandes empresas siendo uno de los principales desafíos que enfrenta la economía ecuatoriana se tendrá que enfrentar.

La política tributaria es un acápite de la política económica, en medida de ello los formadores de dicha política de cada país a nivel mundial, han optado por tomar diferentes decisiones, las cuales estarían basadas en la postergación del pago de impuestos, esto en 
medida del conocimiento general en torno a los problemas de liquidez existente de las empresas a nivel mundial (González, 2020).

Los tributos constituyen una parte sustancial del presupuesto general del Estado, conformado por los ingresos públicos no petroleros como los impuestos, contribuciones, tasas, servicios públicos, donaciones multas entre otros, a fin de incrementar recursos para las arcas fiscales que luego deben ser revertidos en beneficio del país.

De allí que es importante que tanto las micro, pequeñas y medianas empresas, desplieguen esfuerzos para mitigar la emergencia sanitaria de COVID- 19, por consiguiente, las Mipymes tienen la imperiosa necesidad de aplicar la normativa legal vigente, considerando temas en materia de tributos, contabilidad, finanzas, y demás disposiciones, en articulación con el entorno de los negocios, societario y laboral y las disposiciones que el gobierno ha emitido para tratar de aliviar en algo la situación financiera de liquidez en las empresas.

La presente investigación es parte del proyecto de investigación denominado "La importancia de la información contable y financiera ante la incertidumbre del COVID-19 en las Mipymes en el entorno de los negocios en la región 6", el mismo que se justifica porque contribuirá desde una perspectiva teórica académica a dar salida a los problemas de las Mipymes, desde el punto de vista del contenido tributario y contable, las microempresas pueden mantenerse y no desaparecer.

\section{Metodología}

En este apartado de la investigación corresponde examinar algunos aportes teóricos sobre el tema tributario, se utilizó para llevar a cabo el estudio, el paradigma de investigación positivista, tipo de investigación basada en un diseño de campo no experimental y transeccional o transversal con apoyo documental, Según, Tamayo (2003) establece que, en la investigación de campo, los datos se recogen directamente de la realidad, razón por lo que se les denomina primarios, según el precitado autor su valor radica en que permite cerciorarse de las verdaderas condiciones en que se han obtenido los datos, lo cual facilita su revisión o modificación en caso de surgir dudas (p.65).

El nivel de investigación fue la descriptiva, según, Arias (2016), señala que: "La investigación descriptiva consiste en la caracterización de un hecho, fenómeno, individuo o grupo, con el fin de establecer su estructura o comportamiento" (p.24). De allí que se corresponde con el nivel descriptivo en función del objetivo general planteado, la población estuvo estructurada por tres sectores escogidos, microempresas, considerando la base del catastro del SRI, del 2021, así Azuay con 45.814, Cañar 10.497 y Morona Santiago 11.300, total 67.611 microempresas de la Zona 6 del Austro, de las cuales son empresas registradas en la Superintendencia de Compañías por el año 2021 en Azuay 8.843, Cañar 494 y Morona Santiago 341, total 9.678, dando un gran total de 77.289, se determinó el tamaño de la muestra con un $4,50 \%$ de error, determinándose por tanto la muestra $n=471$, la validez de contenido fue realizado mediante el juicio de tres expertos con experiencia en el área de tributación, contabilidad y metodología. 
Por su parte, fue importante analizar en primer lugar, la pertinencia del coeficiente de consistencia interna de Cronbach, el misma habla, sobre el grado en que los ítems miden la homogeneidad. Para determinar la confiabilidad del cuestionario elaborado, se procedió aplicar una prueba piloto a 30 empresas, que no forman parte de la muestra, todos ellos con características similares a los sujetos de este estudio, administrando una escala, de 7 ítems, a una muestra de $\mathrm{n}=30$. De acuerdo con los resultados anteriores, se concluyó que la escala tiene una confiabilidad de consistencia interna muy alta, suficientemente alta como para ser considerada fiable. En conclusión, la confiabilidad del instrumento fue de 0,9 muy alta, así mismo, fue sustancial la utilización de la herramienta estadística para el desarrollo de la investigación, recurriéndose a la estadística descriptiva, lo que permitió la recolección, organización, análisis y presentación de datos con el apoyo de cuadros, tablas y figuras y los resultados obtenidos de la aplicación de los cuestionarios en relación con los objetivos planteados del presente estudio, recurriéndose a la estadística descriptiva mediante el software libre SPSS, versión 26.

El análisis de los datos es una parte esencial de toda investigación, en tal sentido, Hernández, Fernández, y Baptista (2016), sostienen que "el procedimiento que se sigue para analizar los datos consiste en: Una vez que los datos se han codificado, transferido a una matriz, guardado en un archivo y "limpiado" los errores, el investigador procede a analizarlos utilizando un programa computacional" (p.272). En base a lo cual se procedió a inspeccionar, limpiar y transformar datos con el objetivo de resaltar información útil, lo que sugiere conclusiones, y apoyo a la toma de decisiones.

Posterior a los procedimientos que condujeron a reunir datos con el propósito específico de estructurar un análisis de la normativa tributaria, se procedió a revisar los datos o respuestas obtenidas mediante Google forms. Las respuestas a los cuestionarios se recopilan de forma automática y ordenada en formularios, con figuras y datos de las respuestas en tiempo real, que fueron procesados, analizados e interpretados, considerando el uso de la triangulación, validez, confiabilidad y contrastación de los instrumentos.

\section{Fundamentación Teórica}

El marco teórico constituye la base donde se sustentó el trabajo de investigación, representa un sistema coherente y funcional de la información tributaria ante la incertidumbre del COVID-19 en el contexto de las Mipymes, en el entorno de los negocios en la región 6 , ante la emergencia sanitaria que se ha presentado en todo el planeta tierra por la presencia del Coronavirus, para ello fue necesario acudir a información bibliográfica.

Por su parte, en nuestro país, y de manera particular en la región zona 6, surge la necesidad de reprogramar y reorganizar desarrollo productivo de las pequeñas y medianas empresas, con protocolos que permitan volver paulatinamente a la normalidad, para esto existen convenios entre entidades públicas y privadas que van configurando la nueva manera de reiniciar el trabajo en cada una de las Mipymes, con actividades comerciales, para 
enfrentar esta desfavorable situación en correcta relación con las medidas sanitarias que impidan una ola de contagios no deseados, se está impulsando una serie de estrategias innovadoras para reactivar la producción como el teletrabajo, el trabajo por turnos, entre otros.

En consecuencia, el problema que de forma más clara e intensa ha influido en las estructuras económicas, sociales y políticas de finales del siglo XX e inicios del siglo XXI ha sido el de la globalización económica. Este fenómeno que se define como la creciente interdependencia económica entre todos los países, provocada por el aumento del flujo de bienes y servicios, de capitales y por la difusión de la tecnología y de la información tributaria y contable, ha generado un contexto internacional de interacción entre las economías y una desaparición virtual de las fronteras (Carpio, 2012), dando origen a la planificación tributaria internacional entendida como una serie de actos o actuaciones lícitas del contribuyente, cuya finalidad es invertir eficientemente los recursos destinados al negocio de que se trata con la menor carga impositiva, dentro de las opciones que el ordenamiento jurídico contemple.

Toda planificación fiscal persigue minimizar la carga tributaria derivada del ejercicio de una actividad mercantil o de la tenencia de un patrimonio mediante la elección de la vía de acción más eficiente entre todas las alternativas legalmente posibles. Cualquier decisión del obligado tributario que permita minorar sus obligaciones tributarias y que no se oponga, ni siquiera indirectamente, a lo dispuesto en la normativa tributaria.

Nicole (2017) Máster en Economía de University College London, Especialista en temas de microeconomía, regulación y defensa de la competencia menciona que: El tributo es un pago que el Estado exige a sus ciudadanos con el fin de financiar sus actividades y/o políticas económicas, es una prestación pecuniaria que el Estado a través de la Administración Pública puede exigir a los ciudadanos de un país o territorio. La cuantía y período de pago de los tributos se encuentra especificada por ley y su incumplimiento puede llevar a sanciones monetarias y/o la cárcel.

Según, la Comisión Económica para América Latina y el Caribe -CEPAL, (2019) examina algunos elementos de la política tributaria que son de utilidad para impulsar el cumplimiento de la Agenda 2030 para el Desarrollo Sostenible, así como la movilización de recursos internos. En el capítulo II, se analiza la tributación y fiscalización de la economía digital en la región, destacando los cambios en los modelos de negocio que esta supone y los desafíos que estos cambios plantean para la política tributaria y la fiscalización, puesto que los sistemas tributarios diseñados en una época anterior presentan una serie de puntos débiles que favorecen la erosión de los ingresos fiscales. En particular, se revisan las medidas unilaterales que países de la región han adoptado y que apuntan a cerrar los espacios de elusión y cobrar los impuestos derivados de las actividades de la economía comercial y digital.

No obstante, el poder tributario es un atributo que dimana de la esencia del poder público del Estado, por el cual tiene la capacidad jurídica para imponer tributos a sus 
administrados. Por tradición se ha considerado que la potestad para establecer tributos, acuñar moneda y declarar la guerra, constituye el núcleo identificador de la soberanía política. La competencia para establecer tributos ha sido siempre uno de los distintivos tradicionales de la soberanía política (Mongrovejo, 2010). De allí se deriva la capacidad estatal para imponer tributos como cualidad inherente a su soberanía, y en la órbita propia de un Estado de Derecho, se legitima por estar formalmente reconocida en su cuerpo político y jurídico supremo la Constitución Política o Carta Magna.

En lo que respecta al Ecuador, así como en cualquier parte del mundo, el Estado busca solventar sus gastos optando por imponer lo que se conoce como impuestos, de esta manera todos los ciudadanos económicamente activos, se verán obligados a manejar una parte del dinero destinado al Estado, es decir tanto al vender como al comprar ciertos productos, se deben aumentar el 12\% de Impuesto al Valor Agregado (IVA), este es un porcentaje del precio original, Impuesto a la Renta (IR), Impuesto a la Renta sobre ingresos provenientes de Herencias, Legados y Donaciones, Impuesto a la Salida de Divisas (ISD), Impuesto a los vehículos motorizados (IVM), Régimen Impositivo Simplificado Ecuatoriano (RISE), regalías, aranceles, patentes, impuestos seccionales y demás tributos, de esta manera todos los ciudadanos aportan al Estado, al igual que las Mipymes generan gravámenes por concepto del IVA, IR, ICE, IAE, entre otros, para el manejo y control de un fondo monetario el cual será destinado a bienes y servicios públicos.

Por otro lado, de conformidad con el artículo 300 de la Constitución de la República del Ecuador (2008), el régimen tributario se regirá por los principios de generalidad, progresividad, eficiencia, simplicidad administrativa, irretroactividad, equidad, transparencia y suficiencia recaudatoria. Se priorizarán los impuestos directos y progresivos, la política tributaria promoverá la redistribución y estimulará el empleo, la producción de bienes y servicios y conductas ecológicas, sociales y económicas responsables.

De la misma manera, la Ley Orgánica de apoyo humanitario (2020), para combatir la crisis sanitaria derivada del COVID-19, tiene por objeto establecer medidas de apoyo humanitario, necesarias para enfrentar las consecuencias derivadas de la crisis sanitaria ocasionada por el COVID-19, a través de acciones tendientes a mitigar sus efectos adversos dentro del territorio ecuatoriano; que permitan fomentar la reactivación económica y productiva del Ecuador, con especial énfasis en el ser humano, la contención y reactivación de las economías familiares, empresariales, la popular y solidaria, y en el mantenimiento de las condiciones de empleo (p.6).

Otro aspecto a considerar es la evasión tributaria definida como una conducta ilícita del contribuyente, dolosa o culposa, consistente en un acto o en una omisión, cuya consecuencia es la sustracción al pago de una obligación tributaria que ha nacido válidamente en la vida del derecho, mediante su ocultación a la administración tributaria, en perjuicio del patrimonio estatal (Carpio, 2012). 
Referente a la Ley Orgánica de Simplificación y Progresividad Tributaria (2019), y el Reglamento a la Ley Orgánica de Simplificación y Progresividad Tributaria (2020), en la actualidad los microempresarios o comerciantes, se ven inmersos en la obligación de cumplir con la administración tributaria en las distintas contribuciones fiscales que su actividad económica demanda, de acuerdo a las últimas resoluciones, considerando la pandemia del coronavirus que aqueja al país y el mundo.

Es importante señalar la necesidad de propender a una mejor distribución de la riqueza enmarcada en los Objetivos del Plan Nacional del Buen Vivir Toda una Vida PNDTV (2017-2021), al Eje 2 "Económica al servicio de la sociedad", donde prevalece el concepto de que es necesario: "implementar políticas fiscales integrales e inclusivas que tiendan a Fortalecer la cultura tributaria basada en el principio de corresponsabilidad fiscal y solidaridad; Mejorando la eficiencia y la progresividad en la recaudación; optimizando la calidad del gasto; Así como perfeccionando el perfil de vencimientos del financiamiento público.” (p.65)

Conforme, el objetivo 7 del Plan Nacional de Desarrollo Toda una Vida PNDTV (20172021), que se refiere a la necesidad de incentivar una sociedad participativa, con un Estado cercano al servicio de la ciudadanía para lo cual, determina como una de sus políticas, mejorar la calidad de las regulaciones y la simplificación de trámites, para aumentar su efectividad en el bienestar económico, político social y cultural.

De igual forma, la Constitución de la República del Ecuador (2008), en el artículo 135 establece la iniciativa popular exclusiva para el presidente de la república respecto a su potestad de elevar proyectos de ley a fin de crear, modificar o suprimir impuestos, aumentar el gasto público o modificar la división político administrativa del país.

Por otra parte, el Art. 6 del Código Tributario del Estado Ecuatoriano (2020), referente a los fines de los tributos, manifiesta: que "los tributos, además de ser medios para recaudar ingresos públicos, servirán como instrumento de política económica general, estimulando la inversión, la reinversión, el ahorro y su destino hacia los fines productivos y de desarrollo nacional; atenderán a las exigencias de estabilidad y progreso sociales y procurarán una mejor distribución de la renta nacional", (p.2).

Según, el Código Orgánico de la Producción, comercio e inversión -COPCI. (2010), las Mipymes son proveedoras de servicios, productos o insumos para otras compañías de amplia cobertura de mercado local, regional, nacional e internacional. Las micro, pequeñas y medianas empresas, dentro del tejido nacional empresarial aportan de manera significativa al desarrollo productivo y económico del país, de sus beneficios líquidos, aportan con el pago de tributos al erario nacional.

Es importante señalar que a través del portal web de la Cámara Ecuatoriana de Comercio Electrónico - CECE (2020), se coloca a disposición de sus usuarios productos de primera necesidad, comida, bebidas; además su contenido es gratuito para acceder a webinars (clases en línea), sumado a una mínima parte de artículos electrónicos, entre otros, 
generando un atractivo que permite ingresar a las arcas fiscales algo de impuestos por la facturación del sitio.

De igual forma, la Ley Orgánica de Simplificación y Progresividad Tributaria (2019), instituye un régimen tributario simplificado, con dos objetivos fundamentales que consisten en facilitar el cumplimiento de las obligaciones tributarias y los deberes formales de los sujetos pasivos o contribuyentes; y precautelar la sostenibilidad fiscal del país a largo plazo.

Del mismo modo, es necesario reconocer el fomento a la actividad de exportación y a la generación de nuevos emprendimientos, según la Ley Orgánica de Emprendimiento e Innovación (2020), publicada en el suplemento del registro oficial de fecha 28 de febrero de 2020, cuyo objetivo es fomentar el emprendimiento e innovación en el Ecuador, promoviendo el fomento a la actividad de exportación y a la generación de nuevos emprendimientos como ejes transversales de la política pública y económica, puesto que estas actividades permitirán dinamizar la economía y la generación de tributos.

Es importante señalar, que para efectos tributarios la categorización para ingresar al régimen impositivo para microempresarios es aplicada y controlada por el Servicio de Rentas Internas (SRI), en función de la información que reposa en sus bases de datos respecto del monto de ingresos, costos y gastos.

\section{Resultados}

Los resultados, constituyen hallazgos derivados del presente estudio, en correspondencia con los objetivos planteados en la investigación, con el objeto de analizar la legislación tributaria correspondiente a las Mipymes, en el contexto de los negocios ante la presencia del COVID 19, en una relación sinérgica entre las micro, pequeñas y medianas empresas y las normativas tributarias. La tabulación e interpretación de los datos obtenidos en los cuestionarios dirigidos a los actores fueron de 7 ítems.

Figura 1. Actividades principales de las empresas.

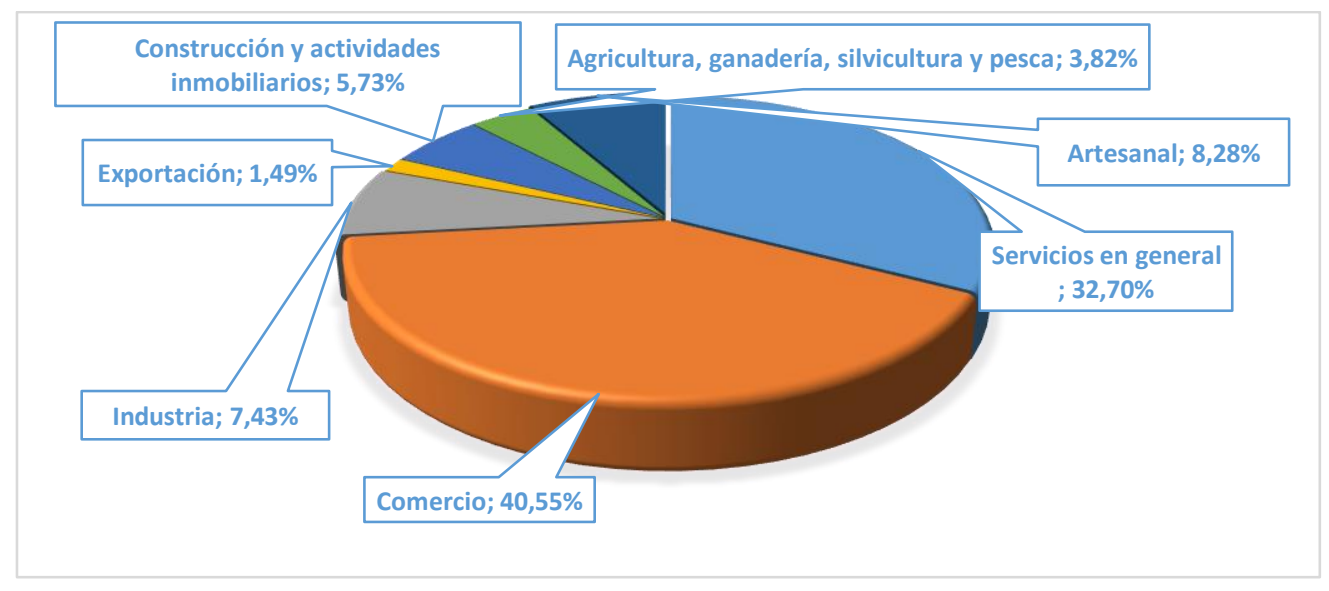

Fuente: Elaboración propia (2021). 
La actividad empresarial es un proceso con fines comerciales o industriales para el beneficio de las personas que colocan en riesgo su capital y contingente; por lo tanto, supone el desarrollo de cualquier compañía con el fin de conseguir aumentar sus ganancias y su potencial en un mercado competitivo.

Entre la población encuestada se encontró que la mayoría de las empresas se dedican al comercio en un 40,55\%, demostrando la importancia de dicha actividad en nuestro país, seguida por otras actividades como servicios generales $32,70 \%$, siendo estas dos primeras las grandes participes de la economía nacional, luego tenemos al sector artesanal con el $8,28 \%$, este sector al no tener demasiada fuerza ante otras actividades no significa que no sea potencial, ya que el mercado artesanal tiene una función muy importante y cada vez crece más e incluso podría llegar a ser potencia de mercado con ayuda de capacitaciones que ofrece el SECAP y algunos incentivos por parte de los entes a los que se rigen este sector, en tanto que la industria representa un $7,43 \%$, el sector industrial dentro de la zona 6, no es muy grande en comparación con otras regiones, ya que para desarrollar actividades industriales se necesitan varios permisos y cumplir con normas ambientales adicionales.

El sector de la construcción y actividades inmobiliarios 5,73\% el sector inmobiliario cada vez crece, y poco a poco va teniendo su espacio dentro del mercado y son más las personas y empresas que deciden invertir en este sector. Así mismo el sector de la agricultura, ganadería, silvicultura y pesca $3,82 \%$ es sorprendente como se van perdiendo cada vez el tema de la agricultura, pero se puede entender que se debe a la migración por un lado y por otro lado porque las ciudades y pueblos se van desarrollando y prefieren incursionar en actividades más fiables, por último el sector de exportación 1,49\%, es un sector que se debería priorizar y ayudar a su crecimiento a futuro, ya que sería una buena entrada de divisas al país y por ende permitiría un crecimiento sostenido a las empresas.

Figura 2. Tamaño de las empresas, según el número de empleados.

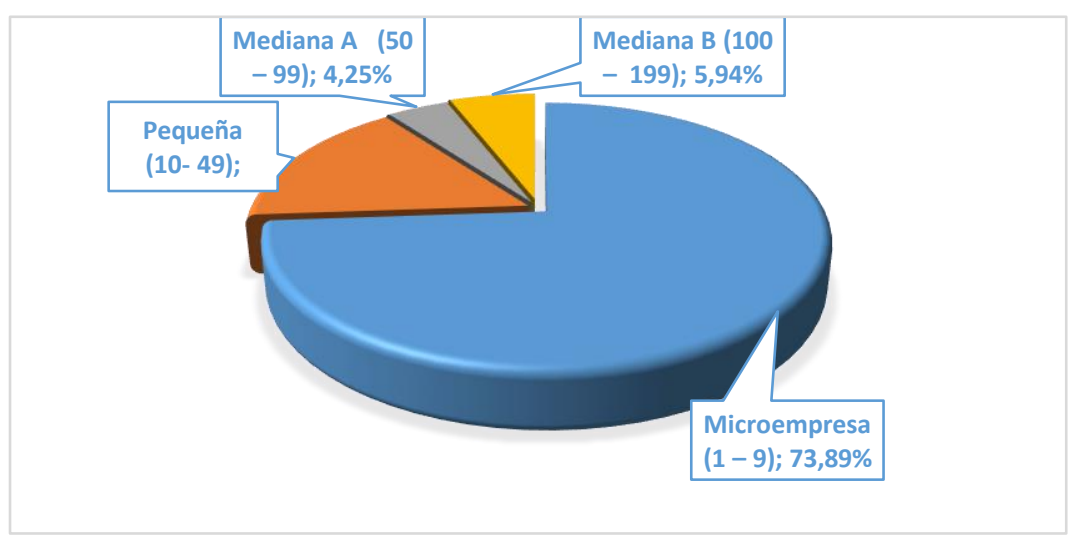

Fuente: Elaboración propia (2021).

En lo que respecta al tamaño de la empresa, según el número de empleados como muestra el gráfico, las pequeñas y medianas empresas junto a las microempresas tienen mayor representatividad en cuanto al tamaño de las empresas encuestadas, el 73,89\% afirmó ser 
una Microempresa (1-9) trabajadores, demostrando el valor y poder en el mercado, los ingresos percibidos por las microempresas por fuentes distintas a la actividad empresarial se sujetarán al régimen general del impuesto a la renta y será de aplicación obligatoria, por su parte el $15,92 \%$ Pequeña empresa (10-49) siendo en su mayoría empresas de responsabilidad limitada, que son sociedades mercantiles cuya responsabilidad está limitada al capital aportado, y por lo tanto, en el caso de que se contraigan deudas, no responden con el patrimonio personal de los socios, sino al aportado en la empresa limitada, el 4,25\% mediana A (50-99) perteneciendo al igual que la anterior a las de responsabilidad limitada y también sociedades anónimas, en su mayoría, y por último el 5,94\% mediana B (100-199) la mayoría de empresas que se encuentran en este grupo son sociedades anónimas, que integran sociedades mercantiles capitalistas nacidas para las grandes acumulaciones de capital.

La información recogida permitió determinar que en el Ecuador se cuenta con una gran cantidad de Mipymes en las áreas comercial, servicios e industrial, las mismas que son fuentes de empleo. Por su relevancia en el mercado comercial y laboral en zona 6, acaparan un rol muy importante en la economía. Sin embargo, presentan también algunas dificultades a nivel global ante la presencia de la pandemia del COVID 19.

Figura 3. Régimen tributario.

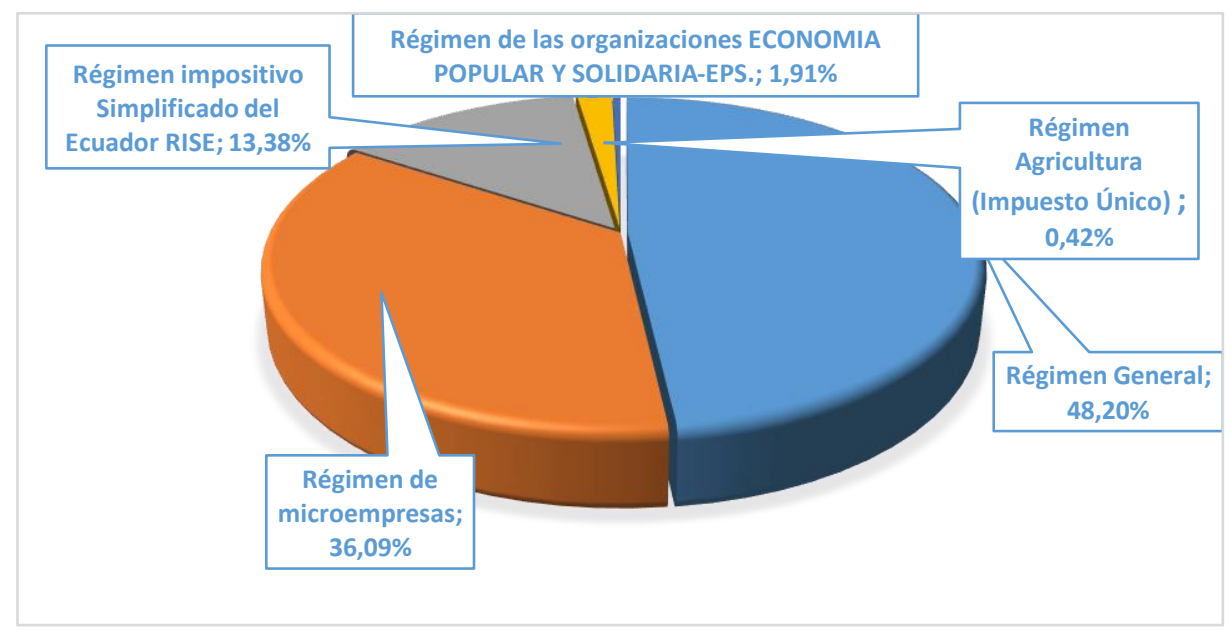

Fuente: Elaboración propia (2021).

El grafico $\mathrm{N}^{\circ} 3$ evidencia los regímenes establecidos en la normativa tributaria, cuya clasificación presenta distinciones en cuanto a su obligación a emitir y entregar comprobantes de venta autorizados por el SRI por sus transacciones, presentar declaraciones de IVA y realizar retenciones de impuesto a la renta, obligación de llevar contabilidad. En el Régimen General 48,20\%, es decir que su carga y sus obligaciones tributarias no se encuentran acogidas a ningún régimen impositivo especial, cumplirán con las demás obligaciones de acuerdo al calendario tributario como declaración de impuesto a la renta, presentación de anexos transaccionales, entre otros.

El análisis indicó, que se encuentran en el Régimen de microempresas el 36,09\%, que es un régimen obligatorio, aplicable al IR, IVA e ICE; también incluye a emprendedores que 
cumplan con la condición de microempresas según lo establecido en el Código Orgánico de la Producción, Comercio e Inversiones y la Ley de simplificación y progresividad tributaria y los reglamentos correspondientes.

De acuerdo con el régimen impositivo simplificado del Ecuador-RISE el 13,38\%, es un régimen de inscripción voluntaria que, a diferencia del régimen general, no paga ni realiza la declaración de impuestos IVA e IR. En su lugar, paga una cuota mensual fija de acuerdo a la actividad económica y categorizada por rangos según sus ingresos o ventas anuales.

Por otro lado, el régimen de las organizaciones Economía Popular y Solidaria (EPS) el $1,91 \%$ tiene por objeto, reconocer, fomentar y fortalecer la economía popular y solidaria y el sector financiero popular y solidario en su ejercicio y relación con los demás sectores de la economía y con el Estado, reconociendo su presencia a través de la Ley Orgánica de Economía Popular y Solidaria (LOEPS), denominando en su art. 1 a la EPS como una forma de organización económica en la que sus integrantes, ya sea individual y colectivamente, organizan y desarrollan procesos de producción, intercambio, comercialización, financiamiento y consumo de bienes y servicios mediante relaciones basadas en la solidaridad, cooperación y reciprocidad, situando al ser humano como sujeto y fin de su actividad y razón de ser.

Por último, el régimen de la agricultura con el 0,42\%, este régimen se aplica a los ingresos provenientes de actividades agropecuarias de origen, agrícola, avícola, pecuario, apícola, canícula y carnes que se mantengan en estado natural, según el art. 27.1 de la Ley Orgánica de Simplificación y Progresividad Tributaria 2019 (pg.10).

Figura 4. Carga impositiva.

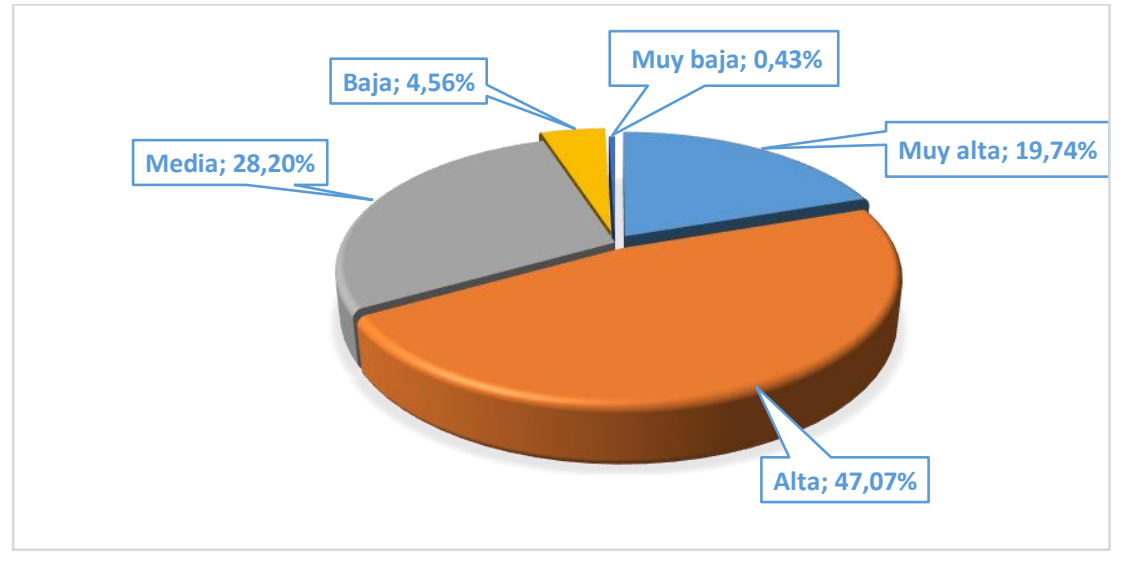

Fuente: Elaboración propia (2021).

El análisis de la figura $\mathrm{N}^{\circ} 4$ indica que el 47,07\% de las empresas creen que la carga impositiva que pagan es alta considerando que incluye impuestos, aranceles, contribuciones entre otros. Este es un indicador importante debido a que puede esgrimir de guía para las autoridades que diseñan las políticas fiscales, particularmente en la estructuración del sistema impositivo. Con esta información la administración tributaria puede conocer, por ejemplo, qué segmento de la población o actividad económica está aportando en mayor o menor cuantía al fisco y el grado de aceptación de estos tributos. 
Igualmente, el 28,20\% los encuestados, piensa que la carga que pagan es media considerando que al reducir la carga tributaria podría ser un mecanismo para promover el consumo y generar una mayor demanda de bienes y servicios, dinamizando la reactivación económica del país. Así mismo, los factores que podrían causar un incremento de los tributos que recauda el SRI serían: fortalecimiento de la cultura tributaria, simplicidad, la eficiencia, el crecimiento económico, el aumento de la base de contribuyentes y principalmente la lucha contra la elusión y defraudación tributaria.

Por otra parte, el 19,74\% señala que hay una carga tributaria muy alta que está dada por la brecha entre una economía que aporta y una que no, mientras que el 4,56\% cree que es baja y solo el $0,43 \%$ de la totalidad de las empresas piensa que es muy baja la carga impositiva que pagan, los tributos constituyen los ingresos fiscales del gobierno como porcentaje del Producto Interno Bruto del país. El tipo impositivo es el porcentaje que se paga por concepto de tributo sobre un ingreso, bien, o transacción económica. Finalmente, el ingreso fiscal es el dinero que ingresa a las arcas gubernamentales producto de los impuestos. En definitiva, cabe mencionar que una vez consolidados los resultados del estudio se desprende que la carga tributaria en Ecuador es percibida como alta.

Figura 5. Flujo de efectivo para cumplir con obligaciones tributarias

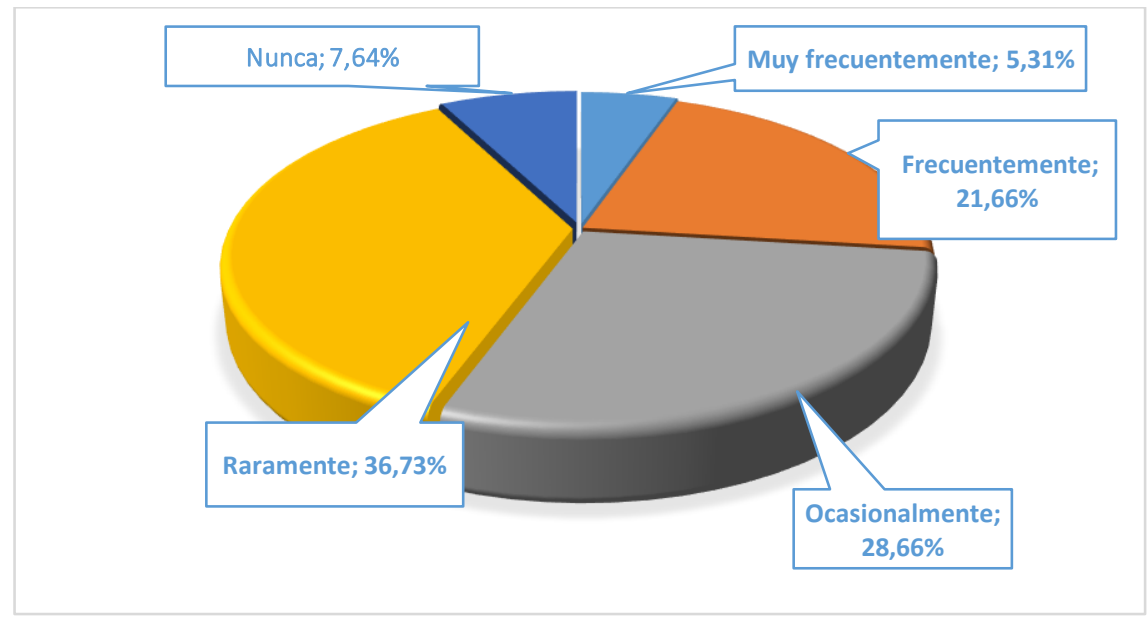

Fuente: Elaboración propia (2021).

Al analizar la figura $\mathrm{N}^{\circ}$, las empresas, independientemente de las actividades que realizan, necesitan de información financiera confiable, como la que proporciona el estado de flujo de efectivo de manera que se conozcan los detalles de los flujos de fondos de un período económico determinado, las entradas y salidas de efectivo por actividades de operación, inversión y financiamiento, datos que servirán a la administración de la empresa para la toma de decisiones. La obtención de efectivo es uno de los principales objetivos que persiguen los negocios, por ello, la mayoría de sus actividades buscan generar una adecuada liquidez con el fin de contar con los recursos suficientes para financiar las operaciones de la empresa, invertir para generar crecimiento, cubrir sus deudas a proveedores, empleados, préstamos bancarios y demás actividades, dentro de los plazos establecidos y devolver a sus inversionistas un rendimiento satisfactorio. 
Según, los datos recopilados se puede ver que el número predominante es el $36.73 \%$ asignado a raramente, esto nos quiere decir que por la presencia del COVID 19 gran parte del flujo de las Mipymes es limitado para cubrir sus actividades empresariales y pagar sus tributos en los tiempos establecidos, por otro lado, tenemos un 28,66\% ocasionalmente, el $21,66 \%$ frecuentemente y el 5,31\% muy frecuentemente, que totalizando la tendencia da $56,23 \%$ que es positivo ya que más de la mitad de los encuestados cuentan con un flujo para cumplir a tiempo con sus obligaciones tributarias, sin embargo, esta es la percepción de los encuestados, quedando pendiente un análisis más profundo que nos muestre si los resultados financieros sostienen este discernimiento. Se evidencia entonces, que la percepción de los contribuyentes y su situación financiera muestra un cierto nivel de estabilidad económica ya que únicamente el 7,64\% es negativo y no estaría en condiciones de cumplir con la administración tributaria.

Figura 6. Incentivos tributarios en época de COVID 19

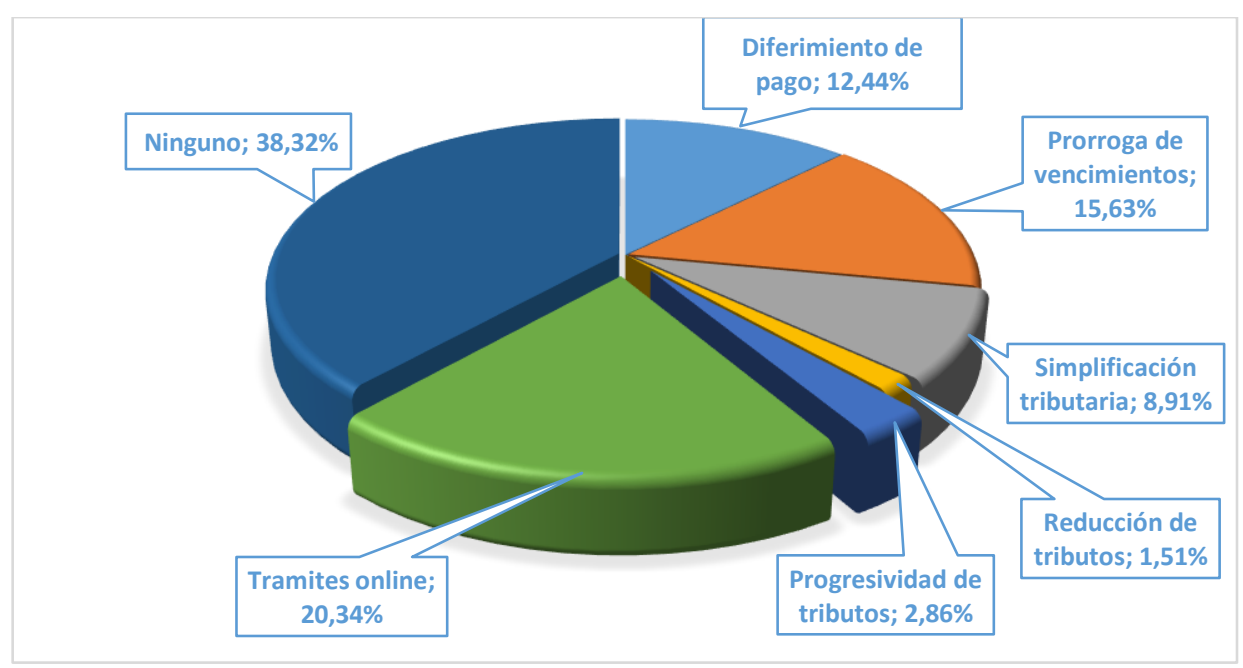

Fuente: Elaboración propia (2021).

La información recogida permitió determinar en la gráfica $\mathrm{N}^{\circ} 6$ la correspondiente articulación con las resoluciones tributarias generadas ante la presencia del COVID 19, que se han dado desde finales del año 2020, hasta la actualidad, se han abierto oportunidades e incentivos para las nuevas inversiones, teniendo como condición fundamental la generación de empleo. La política económica del país tiene como objetivo primordial, lograr una estabilidad económica a través de la producción a su máximo nivel, lo cual va de la mano con la atracción de la inversión extranjera y el impulso a las industrias locales, que permita ampliar la capacidad productiva de bienes y servicios y la generación de ocupación que sea sostenible en el tiempo.

La aplicación oportuna y aprovechamiento de los incentivos tributarios, permitirá a las nuevas inversiones optimizar sus recursos y lograr la permanencia de su negocio, impulsando la economía.

La información expresada en el gráfico muestra el diferimiento de pago del 12,44\%, prórroga de vencimiento el $15,63 \%$, simplificación tributaria el 8,91\%, reducción tributaria el $1,51 \%$ y progresividad de tributos el $2,86 \%$, resultando preocupante ya 
que si se suma las tendencias alcanza el $41,35 \%$ que es una cifra reveladora del total de los datos, traducido en un alto porcentaje de contribuyentes que estuvo a la espera de poder cumplir con sus obligaciones tributarias, o solicitó un plan de pagos para su cumplimiento fiscal y de esta manera acogerse a los incentivos tributarios.

El análisis indicó que el 38,32\%, no se ha acogido a ningún incentivo, talvez por desconocimiento, por un lado, especialmente en el sector microempresarial y por otro debido a la crisis económica, y al escaso flujo del circulante que no han permitido todavía una recuperación financiera, así que, este es un claro ejemplo de la crisis que está atravesando nuestra región, país y el mundo.

Por último, tenemos que el $20,34 \%$ ha reaccionado bien a la virtualización de los trámites tributarios, y han realizado sus diligencias a través del portal SRI en línea www.sri.gob.ec, únicamente con su usuario y contraseña, para ello inicialmente hubo la necesidad de contar con la firma electrónica. Los trámites ingresados en SRI en línea cuentan con el número de identificación del contribuyente con el que se autentifique y ofrece los siguientes beneficios: Inscripción del RUC para personas naturales ecuatorianas y extranjeras residentes, actualización del RUC de personas naturales, cancelación del registro único de contribuyentes, exoneración del impuesto anual a la propiedad de vehículos, motorizados y del impuesto ambiental a la contaminación vehicular, otras transferencias de dominio de vehículos con ejecución de póliza de seguros por pérdida total, inscripción del RUC para sociedades bajo control de la Superintendencia de Compañías, inscripción del RUC para sociedades civiles y comerciales, actualización del RUC de sociedades públicas, entre otros.

Figura 7. Nivel de complejidad de nuevas resoluciones y normativa tributaria.

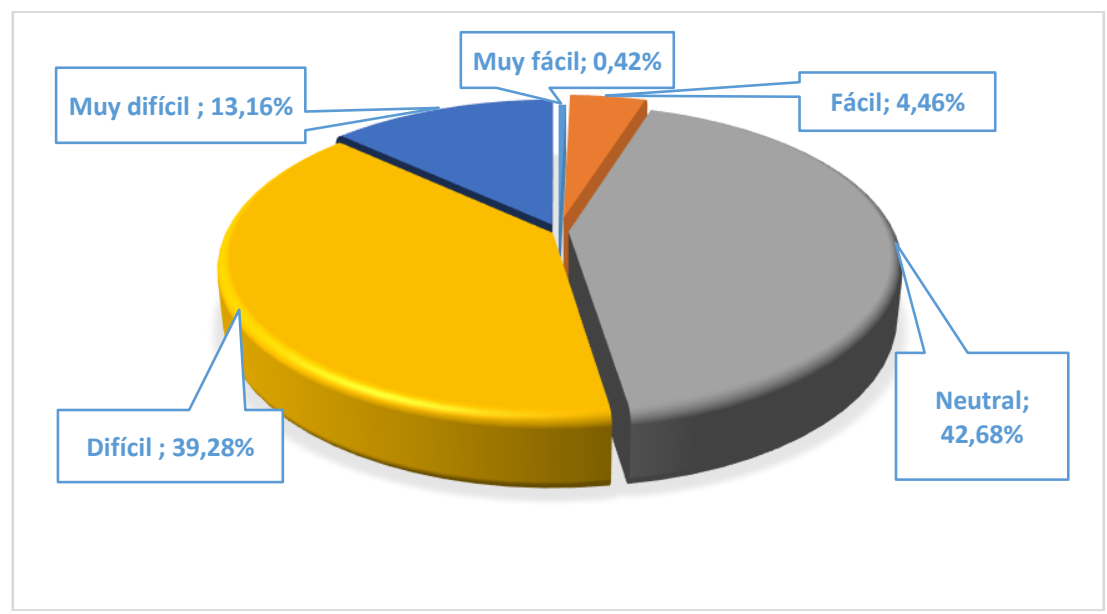

Fuente: Elaboración propia (2021).

Articulando el análisis al grafico $\mathrm{N}^{\circ}$, debemos indicar que en un 39,28\% de los encuestados, les pareció difícil el cumplimiento de las disposiciones emanadas en las resoluciones emitidas por el Servicio de Rentas Internas en su calidad de organismo de control, especialmente las del sector Microempresarial no tuvo claro las normas para la aplicación del régimen impositivo para microempresas, en algunos casos incluía a 
profesionales, choferes, artesanos, compañías, entre otros, y eso fue corregido en algunas ocasiones en el catastro de contribuyentes que debían acogerse al régimen impositivo de microempresas.

Así, mismo 13,16\%, sostienen que es aún más difícil el cumplimiento tributario debido a la inseguridad jurídica que deviene de múltiples cambios en la normativa por un sinnúmero de resoluciones emitidas por el SRI, institución que se encarga de la aplicación de la política tributaria, asegurando la recaudación destinada al fomento de la cohesión social, haciéndose necesario analizar a fondo cuáles son los problemas que tienen los contribuyentes que respondieron de forma negativa para así tratar de buscar soluciones y hacer que la mayoría de la población esté satisfecha con estas normativas que son de vital importancia para el sostenimiento de Mipymes ante la presencia del COVID 19.

Según lo establecido en el artículo 38 de la Ley Orgánica de Simplificación y Progresividad Tributaria, en lo principal, el SRI debió efectuar una actualización de oficio del registro único de contribuyentes a los sujetos pasivos que fueron considerados microempresas, y siempre que no desarrollen exclusivamente actividades económicas consideradas excluyentes para este régimen. El SRI publicará anualmente en su página web el catastro respectivo, sin necesidad de comunicación previa actualizará directamente la información en el RUC; los contribuyentes podrán verificar su información.

Por otro lado, con el 42,68\% de encuestados que sostienen su neutralidad, consiste en no tomar partido y renunciar a toda injerencia en un conflicto o diferencia de opiniones, al parecer algunos de ellos están bien asesorados con sus contadores y otros pertenecen al régimen general ya conocido, y no al régimen impositivo para microempresas de recién creación, por supuesto que muchos de ellos debieron haber liquidado, declarado y pagado sus obligaciones con sujeción con las disposiciones previstas para el régimen general que se mantuvieron sin variación.

Por su parte, el 4,46\%, de los encuestados manifestaron que es fácil, y el $0.42 \%$ muy fácil, totalizado tenemos el $4,88 \%$ que sustentan estar enterados de los cambios en materia tributaria, consideran que el reglamento a la Ley Orgánica de Simplificación y Progresividad Tributaria; la recaudación anticipada del Impuesto a la Renta (IR) de los sujetos pasivos o contribuyentes que no se vieron mayormente afectados durante la emergencia sanitaria.

\section{Análisis medidas tributarias}

La aparición del Coronavirus (COVID-19) obligó a las empresas, no solo a nivel local, regional y nacional, si no del mundo entero a suspender sus actividades comerciales, a esto se sumó el cierre de fronteras, el confinamiento obligatorio y las medidas económicas que ha adoptado el gobierno ecuatoriano, ocasionando una crisis social y económica empujando aún más a la pobreza a muchas personas, de acuerdo a lo investigado es procedente citar las acciones en materia tributaria desplegadas por el gobierno y la administración tributaria para combatir los efectos negativos de la pandemia en el ámbito 
económico, desde finales del mes de enero del año 2020 hasta inicios del mes de julio del 2021, siendo las principales las siguientes:

La administración tributaria procedió a suspender, por pocos días el plazo para presentar las declaraciones de impuesto a la renta de sociedades, desde fecha 16 de abril del 2020, y de la declaración del IVA de marzo para todos los contribuyentes desde el 20 de abril del 2020. El resto de plazos para otro tipo de declaraciones se desarrolló normalmente.

El SRI, emitió una nueva versión de formulario de renta sociedades a partir de mediados del mes de abril 2020, así mismo se concedió el diferimiento en el pago de impuesto a la renta y del IVA. Posteriormente conforme decreto se creó detracción de impuesto a la renta para el caso de las instituciones financieras, que corresponde a los servicios de telefonía móvil y sector petrolero, de igual forma fue presentado el proyecto de reforma tributaria, es decir Ley Orgánica de Apoyo Humanitario para combatir la crisis sanitaria derivada del COVID-19.

La pandemia ocasionó una crisis sanitaria y económica que cambió de forma permanente nuestra forma de vivir y de trabajar. Los efectos sobre el sector de los bienes de consumo son profundos y duraderos. Esta crisis alteró nuestra forma de comprar e impulsó enormes cambios estructurales, de allí que es importante tener presente los bienes cotidianos tales como materiales de bioseguridad (mascarilla, alcohol, guantes, trajes especiales, zapatos o botas, entre otros), alimentos, leche y derivados, canasta básica, medicamentos, papel higiénico, snacks, artículos deportivos, domésticos, entre otros.

Por su parte el gobierno a mediados del mes de abril del 2020, por medio de la Asamblea Nacional, impulsó reformas tributarias considerando principalmente algunos ejes como: contribuciones humanitarias y facilidades de pago, régimen de medidas solidarias y de bienestar, cuenta especial de asistencia humanitaria para recaudar recursos de emergencia sanitaria, reformas laborales, régimen temporal para prevenir procesos de quiebra.

Dentro proyecto de Ley Orgánica de Apoyo Humanitario, se dispuso una reducción salarial del presidente, vicepresidente y ministros con una tarifa del $50 \%$, funcionarios públicos con remuneración igual o superior a mil dólares la tarifa del 10\%, funcionarios públicos con remuneración inferiores a mil dólares tarifa según tabla, estuvieron exentos de esta disminución el sector salud, educación y seguridad.

El análisis indicó que existió diferimiento en el pago de impuestos, dirigido a los Microempresas, cuyos ingresos brutos en 2019 no superaron los $\$ 300.000,00$, a los contribuyentes con domicilio tributario principal en Galápagos, a las empresas con actividad económica principal en operación de líneas aéreas, servicios turísticos de alojamiento y/o comidas, o sector agrícola, y a las empresas exportadores habituales, cuyo $50 \%$ de sus ingresos corresponda a exportación de bienes específicamente, conforme NAC-DGERCG20-00000025.

Con relación al impuesto a la renta de sociedades 2019, conforme resolución precedente, la administración tributaria, aplicó diferimiento, cuyos pagos se realizaron en 6 cuotas: 
$10 \%$ en abril, $10 \%$ en mayo ,20\% en junio, $20 \%$ en julio, $20 \%$ en agosto, $20 \%$ en septiembre, el pago se efectuó según el noveno dígito entre el 10 y 28 de cada mes, aquellas Mipymes que no pudieron acceder al diferimiento, se acogieron a las facilidades de pago previstas en el Código Tributario, mediante cuotas ya sean mensuales, trimestrales o semestrales, se debe indicar que el incumplimiento de una cuota acarrea el término del convenio de facilidades de pago a través de débito automático.

En torno a la ampliación de los plazos para presentación de anexos de marzo a abril la administración tributaria consideró lo siguiente: Anexo APS: Accionistas, Partícipes, Socios, Miembros de Directorio y Administradores- mensual, ROTEF: Anexo Reporte de Operaciones y Transacciones Económicas Financieras, Anexo IRBP: Información de Operaciones Gravadas y Relacionadas con el Impuesto Redimible a las Botellas Plásticas No Retornables, Anexo ICE, Anexo MID: Movimiento Internacional de Divisas, Anexo de Notarios, Registradores de la Propiedad y Registradores Mercantiles, AFIC: Anexo de Fideicomisos Mercantiles, Fondos de Inversión y Fondos Complementarios - mensual.

Por otra parte, el Servicio de Rentas Internas, formuló cambios en los porcentajes de retención en la fuente de impuesto a la renta para la adquisición de bienes muebles de naturaleza corporal antes el 1\%, ahora el 1,75\%; actividades de construcción servicios de seguros, arrendamiento mercantil, servicios de comunicación y agencias de publicidad, antes el $1 \%$, hoy el $1,75 \%$, Pagos o créditos en cuenta no contemplados en porcentajes específicos de retención antes el 2\%, ahora el 2,75\%, conforme Resolución NACDGERCG20-00000030. Igualmente el SRI emitió una nueva autoretención de impuesto a la renta (detracción), reforma al Reglamento de la Ley de Régimen Tributario Interno LRTI: Desde el 1 de abril se aplicará una retención mensual del 1,75\% sobre el total de ingresos obtenidos dentro del mes respectivo a instituciones financieras, empresas privadas que presten servicios de telefonía móvil, y el 1,5\% a las empresas que tengan suscritos con el Estado contratos para la exploración y explotación de hidrocarburos, empresas de transporte de petróleo crudo.

De conformidad a la NAC-DGERCG20-00000055, del mes de agosto del 2020, la administración tributaria emitió las normas para el registro, declaración y pago del IVA por parte de los prestadores de servicios digitales no residentes calificados como agentes de percepción del IVA, generado en las importaciones de servicios digitales realizadas por residente fiscales en Ecuador o establecimientos permanentes de no residentes en Ecuador.

El SRI, generó la NAC-DGERCG21-0000002, para aprobar el formulario 125 para la declaración y pago semestral del impuesto a la renta de los contribuyentes sujetos al régimen impositivo para microempresas, así mismo en enero del 2021, según, NACDGERCG21-0000009, se ampliaron los plazos para la presentación del anexo de gastos personales, correspondientes al ejercicio fiscal 2020.

Para el mes de abril de 2021, se formuló la resolución NAC-DGERCG21-00000024, que hace referencia a la ampliación de los plazos para la presentación del anexo de dividendos 
(ADI) correspondiente al ejercicio fiscal 2020, para el mes de agosto de 2021 segundo el noveno digito del RUC. De igual forma a inicios del mes de julio del 2021, la administración tributaria publicó la NAC-DGERCG21-00000032, en la que se amplía el plazo para la presentación de la declaración del impuesto a la renta (IR), correspondiente al primer semestre del 2021, para los sujetos al régimen de microempresas, cuya fecha de vencimiento corresponde a julio del 2021, podrán hacer las declaraciones hasta el mes de octubre del 2021.

Es importante señalar que el Servicio de Rentas Internas con respecto a la recepción de documentos por medios electrónicos durante el período de excepción, según la NACDGERCG20-00000023, aplica a las comunicaciones, consultas, peticiones, solicitudes y requerimientos que los contribuyentes dirijan al SRI, procedimiento para recepción y gestión electrónica mientras dure el estado de excepción, la documentación se pudo presentar por correo electrónico o Quipux con la respectiva firma electrónica del contribuyente.

Es conveniente destacar los trámites electrónicos referente a) Claves: Actualización de correo electrónico para recuperar clave, recuperación de clave; b) RUC: Personas naturales, inscripción, actualización y suspensión de RUC, sociedades, inscripción, actualización y cancelación de RUC, certificados de no inscripción; c) Impuestos Vehiculares Administrados; d) Declaraciones: Declaraciones en línea, modificación de datos de cabecera; e) Facturación: Facturación física, en el mismo sentido, actualmente los trámites digitales se realizan ingresando al portal del SRI trámites electrónicos, allí se ingresa el trámite sin necesidad de firma electrónica y de acudir a los centros de atención, para ello es necesario contar con el usuario y clave de servicios en línea y contar con todos los requisitos de respaldo.

\section{Conclusiones}

A continuación, se exponen las principales conclusiones, integrando los resultados de los cuestionarios, y la técnica de la observación:

- La información recogida en los gráficos $\mathrm{N}^{\circ} 1,2$ y 3 respectivamente, sostiene que la actividad económica con mayor aceptación es el comercio con el 40,55\%, seguido de los servicios con el 32,70\%, bajo la estructura de microempresa representada por el 73,89\% apreciado en el segundo gráfico, en tanto que, en el gráfico 3 se revela que pertenecen al régimen de microempresas en un 36,09\% y en el régimen general un $48.20 \%$, desempeñando un papel protagónico en la economía del país, toda vez que coadyuvan para su progreso y desarrollo, siendo las mismas una herramienta clave, en la recuperación y dinamización económica y social del país en la "postcrisis" por el COVID-19, para ello es imperativo la innovación y la creatividad para un verdadera sostenibilidad económica.

- El análisis de los gráficos $\mathrm{N}^{\circ} 4$ y 5 con respecto a la carga impositiva que pagan las Mipymes en un 47,07\%, sostienen que es alta, por ello consideran que es difícil contar con el flujo del efectivo entre la tendencia de raramente y ocasionalmente 
totalizan el $65,39 \%$, esto hace suponer que las microempresas en el Ecuador, no disponen de recursos para el pago de sus obligaciones tributarias por más que sean mínimas como por ejemplo el pago del $2 \%$ sobre las ventas, debido a un bajo nivel de ventas y acceso al financiamiento con lo que resulta complicado su desarrollo y contar con planes de escala para crecer y desarrollarse.

- Con respecto a los trámites en línea el 20,34\% de encuestados sostienen que es ventajoso realizar sus gestiones mediante el uso de la web para cubrir sus requerimientos en cumplimiento a las disposiciones de la administración tributaria, hoy en día existen varias diligencias que se pueden realizar a través de internet, sin necesidad de desplazarse a los lugares de manera física. Con esto se ahorra tiempo y se gana comodidad, esto se realiza a través de medios electrónicos, que son instrumentos creados para obtener información de forma automatizada y eficiente, de allí que el SRI cuenta con una unidad de técnicos informáticos que está a la altura de servicios de otros países desarrollados, pero siempre en busca de una mejora continua.

- En cuanto a las opiniones emitidas sobre el cumplimiento de las resoluciones del SRI, la tendencia entre difícil y muy difícil representan el 52,44\%, una de las principales causas es la falta de cultura tributaria debido al desconocimiento de la normativa vigente, aspecto que da paso a la evasión y los ilícitos tributarios, al no estar familiarizados a fondo con ciertos términos y el razonamiento como el porqué de la obligación que tienen que cumplir y su contribución al beneficio de la sociedad, por ello la importancia de entender las normativas tributarias las resoluciones y la finalidad de pagar impuestos.

- La Administración Tributaria tiene un papel fundamental en la recaudación de los ingresos, generando estrategias que permitan ampliar el número de contribuyentes que consideren que la carga tributaria es media, promoviendo el consumo y generar una mayor demanda de bienes y servicios, dinamizando la reactivación económica. Es necesario establecer controles que disminuyan la evasión y elusión, especialmente a los contribuyentes de mayores ingresos, verificar la licitud de los gastos, así como fomentar la cultura tributaria.

- Las Mipymes deben generar información confiable, pertinente y concisa, con el fin de que los usuarios de los estados financieros tengan elementos adicionales para generar la reactivación económica, examinar la solvencia y la capacidad de la empresa para generar flujos positivos de efectivo en el futuro, mejorando la situación presentada por el $65,39 \%$ de los encuestados que manifestaron que raramente $\mathrm{u}$ ocasionalmente cuentan con la liquidez suficiente para cubrir sus obligaciones tributarias y por ende para pagar dividendos, intereses, deudas contraídas a proveedores y financiar el crecimiento y generar trabajo.

- Como es lógico la eliminación gradual del impuesto a la salida de divisas, la proporcionalidad es una de las alternativas, lo que alentaría el ingreso de capitales frescos, pero esta decisión debe estar alineada a que los recursos de las inversiones que se encuentren fuera del país, por parte de los ciudadanos ecuatorianos y obviamente los extranjeros, vengan a fortalecer el aparato 
productivo, generen inversión, alienten el empleo, inyecten recursos a la economía para mejorar el nivel de circulante y dar una salida a la crisis, por otro lado, se puedan otorgar créditos blandos con tasas de interés manejables para consolidar el cumplimiento de esas obligaciones fomentando la inclusión financiera y mejorando su récord crediticio.

- Otro aspecto a considerar sería que el sistema financiero debe colaborar con la reactivación económica, restructurando todo crédito que no ha podido ser cancelado, considerando la rebaja de intereses deducibles del pago del impuesto a la renta que están vigentes en esas reestructuraciones.

- Finalmente, los datos contenidos en los cuestionarios traen como resultado, que será importante la eliminación del impuesto a la renta calculado sobre las ventas de las microempresas ya que como se mencionó con anterioridad, afecta considerablemente al flujo de efectivo, constituyéndose en un valor anticipado por impuesto a la renta. Además, este impuesto desnaturaliza el concepto de renta entendida como la diferencia de ingresos menos gastos, convirtiendo un impuesto directo en un impuesto indirecto sobre las ventas, en desmedro de los principios tributarios de progresividad y equidad consagrados en la Constitución de la República, puesto que no se toma en cuenta la capacidad contributiva del contribuyente.

\section{Referencias bibliográficas}

Arias, F. (2016). El Proyecto de Investigación: Introducción a la metodología científica. ( $7^{\text {a }}$ Edición), Caracas - Venezuela. Editorial El pasillo, C.A.

Constitución de la República del Ecuador. (2008). Obtenido de http://goberguayas.gob.ec/pdf/INFORMACIONLEGAL/NORMASDECREACI ON/Norma-Constitucional.pdf

Carpio, R. (2012). Planificación Tributaria Internacional. Retos. Recuperado de file:///C:/Users/Usuario/Downloads/718-

Texto\%20del\%20art\%C3\%ADculo\%20(anonimizado)\%20(obligatorio)-1916-1$10-20160125 \% 20(1) . p d f$

Cámara Ecuatoriana de Comercio Electrónico -CECE (2020), Proyectamos crecimiento de 15 veces más de lo habitual, recuperado de: https://www.eluniverso.com/noticias/2020/04/06/nota/7805850/proyectamoscrecimiento-15-veces-mas-habitual

Código Orgánico de la Producción, comercio e inversión, COPCI, , (2010), Esta Ley fue publicada en el Suplemento del Registro Oficial $N^{\circ} 351$, del 29 de diciembre del 2010.

Código tributario, recuperado el 30 de abril del 2020 de:

https://www.quito.gob.ec/documents/Portal_tributario/Normativa/Ley/CODIGO _TRIBUTARIO_ACT.pdf 
González, D. (2020). Las medidas de tributación ante el coronavirus. Obtenido de Centro Interamericano de Administraciones Tributarias: recuperado de: https://www.ciat.org/las-medidas-de-tributacion-ante-el-coronavirus/

Hernández, S., Fernández, C., \& Baptista, L. (2016). Metodología de la Investigación. México: Mc Graw Hill Educación, 6ta. Edición.

Mongrovejo, J. (2010). El poder tributario municipal en el Ecuador. Quito: Universidad Andina Simón Bolívar, Sede Ecuador; Corporación Editora Nacional; Ediciones Abya Yala.

Nicole, P., (2017). Microeconomía, regulación y defensa de la competencia, recuperado de: (07 de junio, 2017). Tributo.Economipedia.com

La Comisión Económica para América Latina - CEPAL (2019), Políticas tributarias para la movilización de recursos en el marco de la Agenda 2030 para el Desarrollo Sostenible. Impreso en Naciones Unidas, Santiago S.19-00075. ISBN: 978-92-1122016-2.

Ley Orgánica de apoyo humanitario (2020). Gaceta oficial $N^{\circ} 229$, del 22 de junio del 2020.

Ley Orgánica de Emprendimiento e Innovación, (2020), Esta Ley fue publicada en el Suplemento del Registro Oficial No 151, del 28 de febrero del 2020.

Ley Orgánica de Simplificación y Progresividad Tributaria, (2019), Esta Ley fue publicada en el Suplemento del Registro Oficial $N^{\circ} 111$, del 31 de diciembre del 2019.

SENPLADES. (2017). Plan Nacional para el Buen Vivir 2017-2021. Quito: SENPLADES, Gaceta oficial No 681 del 13 de julio del 2017.

Tamayo, M. (2003). El Proceso de Investigación Científica (4ª edición). México. Editorial Limusa.

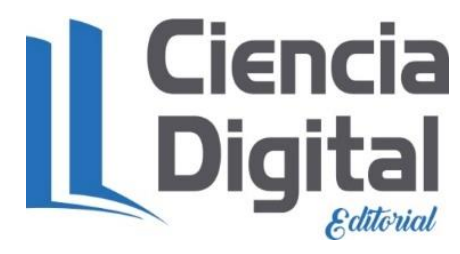




\section{PARA CITAR EL ARTÍCULO INDEXADO.}

Becerra Molina, E., Flores Flores, M. E., \& Cuadrado Sánchez, G. (2021). La fiscalidad en las Mipymes de la región del Austro, en el contexto de la pandemia del COVID-19. AlfaPublicaciones, 3(3), 98-119. https://doi.org/10.33262/ap.v3i3.71

\section{¿Ciencia}

El artículo que se publica es de exclusiva responsabilidad de los autores y no necesariamente reflejan el pensamiento de la Revista Alfa Publicaciones.

El artículo queda en propiedad de la revista y, por tanto, su publicación parcial y/o total en otro medio tiene que ser autorizado por el director de la Revista Alfa Publicaciones.
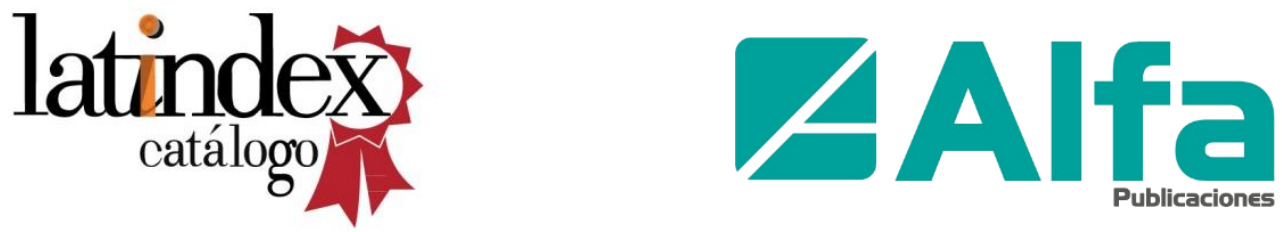